\title{
CORPO, COMUNICAÇÃO E EDUCAÇÃO
}

\author{
Claudio Bertolli Filho* \\ Raquel Lange 0 bregon**
}

\begin{abstract}
Resumo: 0 objetivo deste artigo é discutir as dificuldades de comunicação de conteúdos relacionados ao corpo humano, no contexto dos processos de ensino e de aprendizagem na escola fundamental e média. Através da exposição das necessidades dos alunos e das reticências dos professores, apresenta-se al gumas teorias sociais como estratégia mediadora e viabilizadora do melhor desempenho da ação pedagógica e da contribuição escolar para a constituição do educando enquanto sujeito social.
\end{abstract}

Unitermos: Corpo humano, ensino de Biologia, processos de ensino e de aprendizagem.

Abstract: This article aims to discuss the difficulties in communicating contents related to humam body in the context of the teaching and learning process in the elementary and secondary schools. It was used the statement of student's needs and teacher's reticences. They were analysed through some social theories as mediating strategy to a best performance of pedagogical action and a contribution in constituting the learner as a social being.

Keywords: H uman body; bi ology teaching; teaching and learning processes

Este texto discute os possíveis enquadramentos do corpo humano como objeto de estudo, no contexto do processo de ensino e aprendizagem no âmbito das últimas séries do ensino fundamental e médio. 0 ponto de partida consiste no fato de que os conteúdos abordados no momento de aula e nas tarefas conseqüentes consistem em um momento privilegiado da comunicação humana. Para que esta se efetive, isto é, que ocorra o mínimo possível de "ruído" a ponto de não comprometer a intencionalidade dos sujeitos sociais envolvidos, algumas medidas docentes são vitais, tais como: a clareza na exposição das informações, a recorrência à evidências registradas no cotidiano dos educandos e o relacionamento fluido entre 0 emissor e o receptor da mensagem. Sobretudo é importante que, no processo comunicativo mediado pelo compromisso de ensinar e aprender, ocorra a interação entre as partes envolvidas a tal ponto que se estabeleça uma rotina de reciprocidade e de alternância entre os que ocupam as posições de emissor e receptor da mensagem (Guistan 1994:64).

A condição de alternância entre quem fala e quem ouve abre a possibilidade para 0 diálogo, isto é, para a argumentação e a contra-argumentação presente no discurso. Resultando desse empenho, 0 ato de cognição afinado com a proposta construtivista tem como fundamento primeiro a educação/comunicação enquanto um projeto de exercício e confirmação dos princípios do ensino democrático.

Sob o ponto de vista histórico-antropológico, o momento aula enquadra-se nos parâmetros de um "encontro de culturas" baseado nos crivos geracional, de classe social, de inserção em sub-culturas, como a popular, a científica e a de massa, além de interesses e necessidades individuais. Pensa-se sobretudo em "culturas pessoais" específicas do professor e dos

\footnotetext{
* Professor Assistente D outor do D epartamento de Ciências H umanas da Faculdade de Arquitetura, Artese

Comunicação e do programa de Pós graduação em Educação para a Ciência da Faculdade de Ciências da

Universidade Estadual Paulista - U N ESP - Campus de Bauru. (email: cbertolli@uol.com.br)

** Graduanda do Curso de Comunicação Social (radialismo) da Faculdade de Arquitetura, Artes e Comunicação da

U niversidade Estadual Paulista - U NESP - Campus de Bauru.
} 
al unos que, portadores de saberes diferenciados, não devem conflituar ou anularem-se reciprocamente, mas sim construírem-se e enriquecerem-se mutuamente, contribuindo para que os envolvidos no processo didático-pedagógico dominem novos conteúdos e, a partir disso, vivam suas vidas o mais plenamente possível (Jean 1990:30).

N esse contexto, acreditase que um dos motivos que dificulta o ensino e aprendizado nas disciplinas Ciências e Biologia, especialmente no que se refere ao corpo humano, encontrase na possível dissintonia entre perspectivas e de necessidades que instruem as falas e também os silêncios dos educadores e dos educandos. Assim, o conteúdo que é apresentado como importante de conhecer para uns, não o é para outros e o fluído na fala para uns, mostra-se temeroso de ser dito para outros, ditando as possibilidades de sucesso ou de fracasso do processo pedagógico.

D ados que apóiam tal interpretação podem ser encontrados em experiências recentes dos autores deste texto. A primeira circunstância deu-se no momento de entrevistas com adolescentes que, quando questionados sobre como seus professores abordavam as questões do corpo, confidenciaram unissonamente que, independentemente dos conhecimentos demonstrados pelos professores ou o dinamismo emprestado às aulas, os docentes tendiam a abordar conteúdos que pouco ou mesmo nada interessavam aos alunos, condenando os encontros a serem tediosos, assim como foram qualificados de "chatos" a maior parte dos livros didáticos que tratavam do assunto.

O utra situação vivenciada refere-se ao contato mantido com professores da rede pública de ensino no contexto do Programa de Educação Continuada desenvolvido no município de Santo Antônio do Aracanguá, localizado no Estado de São Paulo. 0 empenho do monitor em enfatizar a multi e a transdisciplinaridade levou os debates a convergirem para questões relativas ao corpo e a sexualidade humana sob o ponto de vista biológico e sócioantropológico. N aquela ocasião, uma parte significativa dos presentes na reunião (que incluía desde docentes com formação em nível de pós-graduação até professores com visíveis lacunas de conhecimento básico) mostrou-se avessa a tal tipo de discussão com os educandos, alegando entre outras coisas que "os alunos ficariam excitados", "o professor seria colocado em ridículo", "seria vulgar discorrer sobre tais coisas", "não cai no vestibular", "o diretor da escola não deixaria que eu falasse sobre isso", chegando um dos professores a afirmar que não falaria nem no encontro e muito menos durante suas aulas sobre tais "porcarias". Ao assim se pronunciarem, os docentes anunciavam um rígida e moralista divisão entre o público e o privado no discurso sobre o corpo, rejeitando iniciativas que fugissem à perspectiva adotada pela maior parte dos textos didáticos. 0 imaginário constitutivo da cultura pessoal dos docentes sobre os seus próprios corpos ditava o silêncio frente aos alunos, aflorando como mais um fator interveniente no processo de ensino e de aprendizagem (Postic 1992:48).

Apesar disso, nesse mesmo encontro, a parcela dos docentes que se mostrava interessada em adotar - ou pelo menos tentar - novas perspectivas para a abordagem do corpo humano dizia-se com dificuldades para executar tal intento pela ausência de informações que viabilizassem novos enfoques. Tal constatação não é nova, nutrindo no momento, na U N ESP de Bauru, uma série de ações que buscam responder questões que tocam mais de perto a expe riência concreta dos educan dos com seus corpos, ações estas que resultaram, inclusive na constituição de grupos multidisciplinares de pesquisa voltados para o tema.

A partir das situações apresentadas e reconhecendo a extensão das lacunas encontradas nos livros didáticos, sobretudo os específicos das áreas de Ciências e Biologia, buscou-se 
contribuir com as discussões sobre o corpo humano enquanto tema de ensino/aprendizagem, esperando que o enfoque adotado neste texto seja útil para uma prática docente centrada na problemática exposta pelos adolescentes. Em continuidade, buscou-se primeiramente conhecer as questões cotidianas enfrentadas pelos jovens estudantes e centradas em seus próprios corpos e a avaliação que eles fazem das aulas e dos textos didáticos voltados para o assunto para em seguida abordar as possibilidades abertas pelas teorias sociais elaboradas sobre 0 tema.

\section{0 adolescente e seu corpo}

0 empenho em conhecer o que os educandos percebem como problemática íntima resultante de sua experiência corporal em sociedade e como isto é abordado - ou não em sala de aula, levou à realização de entrevistas não dirigidas com um grupo de vinte estudantes de ambos os sexos que freqüentam o último ano do ensino fundamental e as várias séries do ensino médio, pertencentes sobretudo às classes médias urbanas.

Segundo a visão apresentada pelo grupo estudado, fica claro que os adolescentes não percebem o corpo humano apenas como uma entidade inteligível mediante a metáfora de uma máquina composta por órgãos, sistemas e funções rigidamente estabelecidas e dotado de uma multiplicidade de denominações complexas e freqüentemente difíceis de serem lembradas após a avaliação escolar. Ainda para os jovens, o discurso científico mediado pelo professor e pelos livros didáticos e paradidáticos se preocupam mais em focar a dimensão interna do organismo, negligenciando sua exterioridade, em um momento de suas vidas em que a aparência física ganha uma aspecto vital na integração social junto à família e ao grupos de amigos, enfim, no meio social em que vivem. Vital porque é nesta fase em que 0 adolescente busca ser aceito socialmente e empenha-se em definir sua imagem e seu estilo, configurando a autonomia de sua personalidade, sua maneira de ser, estabelecendo um "tipo" que ao mesmo tempo que indica suas preferências e fantasias, também se revela como ele próprio percebe e avalia a realidade e reivindica uma posição específica na trama grupal.

$\mathrm{Na}$ tarefa de se apresentar ao mundo, a mídia exerce um papel primordial. Bem mais do que os ensinamentos obtidos em aula, os adolescentes disseram-se instruídos e seduzidos pelas mensagens a que têm acesso através da televisão, das revistas direcionadas para esta parcela do público à qual pertencem e, em menor escala, pela Internet. A indústria da moda, recitada como exemplo pelos depoentes, tendea pontificar a reprodução de modelos corporais representadas por mulher magras, al gumas quase anoréxicas, induzindo muitas jovens a se submeterem a dietas que, sem qualquer tipo de acompanhamento, podem ter conseqüências graves à saúde.

Algumas adolescentes confidenciaram que, desprovidas de outros tipos de orientação, inclusive por parte de seus professores, adotaram dietas preconizadas pela mídia, mesmo quando não estavam acima do peso recomendado, buscando aproximarem seus corpos às imagens de algumas top models cujos nomes foram soletrados com precisão e sem qualquer reticência: Claudia Schiffer, Kate M oss e N aomi C ampbell. Para se assemelhar às tais personagens, umas das depoentes, aluna de oitava série, informou sobre o regimequeadotou para o momento que definiu como uma solenidade social: "Comi uma maçã no almoço e uma pêra no jantar durante uma semana para estar bem magra no dia de viajar para a praia com meus amigos em uma excursão".

A questão estética não se limita apenas ao contingente feminino, despontando como problema a ser enfrentado também pelos rapazes que encontram em seus ídolos 0 
model o corporal a ser imitado. D e Tom C ruise a Arnold Schwarzenegger, passando por muitos outros atores e esportistas adotados pela mídia, vários rapazes revelaram, não sem um certo constrangimento, empenhar tempo e dinheiro para tingirem seus cabelos, adquirirem roupas da moda, freqüentarem academias de musculação e ingerirem anabolizantes para conseguirem o físico condizente com a imagem que consideram a ideal para com este procedimento conquistarem garotas, ganharem o respeito de seus colegas, enfim, postarem-se positivamente frente à rede de sociabilidade. Em um dos casos, representado por um jovem trabal hador, tais atitudes e 0 uso imoderado de fortificantes foram também relacionadas com a preservação do vigor físico e beleza corporal que julga estarem sendo afetados pelo regime de trabalho ao qual se vê diariamente submetido em uma unidade industrial.

Além da dimensão estética, outro tema que foi abordado espontaneamente pelos entrevistados constituiu-se na sexualidade, assunto que, segundo os jovens, desperta muitas dúvidas, medos e curiosidades os quais, de regra, não encontram respaldo e orientação convincente por parte dos professores, mesmo que os adolescentes reconhecessem que muitas perguntas deixam de ser feitas por eles nas aulas por causarem certo desconforto, inclusive devido à reação jocosa dos próprios colegas de classe. Assim, informações sobre doenças sexualmente transmissíveis, gravidez, mudanças no organismo acabam sendo insuficientes apesar de serem apresentadas em sala de aula e abordadas pragmaticamente nos textos didáticos.

Em um dos casos estudados, um adolescente disse que, pelo fato de ter se iniciado sexualmente, amedrontou-se com a possibilidade deter contraído uma doença sexual mentetransmissivivel, procurando seu professor de Ciências durante o intervalo de aula. Ao expor seus receios, recebeu como resposta a advertência que ele não deveria ter feito o que fez e que se quisesse informações que recorresse aos pais ou se dirigisse a um Posto de Saúde, já que a função docente não obriga nenhum professor a tratar do assunto em pauta, ainda mais, fora do momento de aula.

N esse contexto de dúvidas em série, a AIDS desponta como a principal patologia geradora de questões e medos por parte dos adolescentes. Segundo eles, se informações gerais são conseguidas tanto no decorrer das aulas quanto através de palestrantes convidados pelas unidades de ensino, muitas outras enfermidades sexualmente transmissíveis são praticamente esquecidas nas preleções, tais como a gonorréia, a sífilis e o H PV. Essas patologias têm alta incidência entre os jovens e, apesar de disporem de terapêuticas eficientes, se não forem diagnosticadas precocemente, podem resultar em tratamentos prolongados e recuperação demorada.

Além disto, a gravidez foi outro assunto abordado nas entrevistas, sendo que o tema parece ser comentado satisfatoriamente em sala de aula, principalmente quando alguma adolescente da turma engravida, coagindo os professores a dedicarem al gum tempo para explicar o fenômeno e a instruir os alunos sobre as estratégias de como evitá-la. Para além disso, os aspectos psicológicos envolvendo a sexualidade e as transformações percebidas nos corpos adolescentes foram avaliadas como insuficientes, gerando mais dúvidas do que esclarecimentos. Significativo é constatar que os alunos, mais do que seus professores, parecem perceber o momento complexo em que vivem os adolescentes, sendo que um deles avaliou que nas aulas de Biologia deveria ser tratado, pelo menos em algum momento, da fase adolescente da existência na qual "a confluência do físico e do psíquico gera tantos problemas que a gente não sabe o que fazer". E acrescentou: "uma das experiências que temos nessa fase é a do prazer; prazer em relação a tudo, especialmente o que é extraído do nosso próprio corpo eisso não é de jeito nenhum tratado nas aulas, mesmo que seja para falar das causas biológicas do prazer". N esta situação vale lembrar que existe uma relação 
significativa entre o tema sexualidade e o conteúdo tradicional da disciplina Biologia, referente ao prazer sexual como característica importante para a sobrevivência da espécie humana.

Para muitos dos adolescentes consultados, a lacuna não solucionada pelo trabalho docente encontra como possibilidade de orientação o contexto familiar. Q uestionados sobre 0 desempenho de seus pais na orientação sobre o corpo, os jovens qualificaram seus parentes mais próximos ora de conservadores ora de liberais, sendo que, independentemente de tais posicionamentos, al guns progenitores falam abertamente sobre o sexo enquanto que outros se negam veementemente a tratar do assunto. 0 s pais que se empenham em discutir as questões corporais com seus filhos tendem a relacionar o tema com os efeitos maléficos das drogas (inclusive o consumo de tabaco e de bebidas alcoólicas), da violência e especialmente da sexualidade, al guns instruindo com precisão sobre os riscos de infecção pelas D oenças Sexualmente Transmissíveis, outros reportando-se a informações imprecisas registradas nas formulações culturais tradicionais, tais como a relação positiva entre masturbação, doença mental e impotência futura. Apesar de todos os jovens admitirem que os pais preocupam-se com o bem-estar físico dos seus filhos, parece que o elemento direcionador das falas familiares constitui-se em negar aos filhos o direito de uso do corpo, taxado na maior parte das vezes como al go que deve ser usufruído quando os jovens se tornarem adultos.

A representação dos entrevistados sobre seus professores e seus pais confluem para uma mesma avaliação: tantos uns quanto outros mostram-se incapazes de tratar de maneira clara e eficiente as necessidades e as apreensões próprias dos adolescentes em relação aos seus corpos. Configura-se assim uma espécie de círculo vicioso: na ausência de informações convincentes na sala de aula e em casa, os jovens buscam informações na mídia ou, no máximo, junto aos amigos mais próximos, tão adolescentes e portadores de noções duvidosas quanto aqueles que procuram orientações.

No território pautado da ausência ou imprecisão das informações sobre seus corpos, os adolescentes defrontam-se com questões que nunca parecem encontrar respostas claras, preenchidas pelo "acho que" acerca de muitos pontos. Ao mesmo tempo, tomados por uma corpolatria típica da adolescência e insuflada pela mídia, vêem-se indecisos sobre praticamente tudo que diz respeito ao corpo e, informados pelos meios de comunicação tendem a colocar de lado as questões de saúde propriamente dita para se voltarem mais para as questões esté ticas e do emprego do corpo como fonte de prazer para se situarem no contexto social ime diato (Codo, 1985; G allagher, 1992).

Para além disto, alguns temas tornam-se verdadeiros tabus para os adolescentes que tentam evitar conjecturas até mesmo junto aos seus colegas por acharem suas dúvidas e necessidades demasiadamente repugnantes ou anormais. A estruturação de uma imagem sobre o corpo reproduz as luzes e as sombras lançadas pelo ambiente social, favorecendo percepções específicas sobre os riscos e as transgressões relativas ao corpo e, por extensão, à vida em grupo (Rodrigues, 1979 e 1999).

\section{As teorias sociais}

Filhas do racionalismo cartesiano e da filosofia iluminista, as Ciências Sociais hesitaram durante um longo período em analisar o corpo humano como objeto de interesse sócio-cultural. Ao privilegiar o "espírito" como gerador da produção cultural, a Antropologia, em especial, pouco se deteve no estudo das percepções individuais e coletivas nutridas sobre o corpo e a 
experiência corporal, rel egando-as à condição de faits divers, isto é, de escassa importância para 0 entendimento das regras que regem o cotidiano grupal (Turner, 1984:29).

Apesar desse direcionamento, tornava-se praticamente impossível o estudo do H omem e da Sociedade sem levar-se em consideração o corpo humano. Em meados do século XIX, Karl M arX, ao teorizar sobre a vida social nos quadros do capitalismo industrial, talvez tenha sido o primeiro pensador contemporâneo a esboçar uma teoria sobre o corpo, mesmo que simplificando sua complexidade através da recorrência à categoria "força de trabaIho". Para ele, o corpo representa, em primeira instância, uma complexa composição natural dotada de potencialidade de auto-transformação. Enquanto fenômeno produzido pela natureza, o corpo mostrava-se originalmente habilitado para transformar 0 meio natural e, a partir disto, a própria condição humana, isto é, deixar de apresentar-se apenas como força bruta para atingir o patamar da produção de pensamentos, val ores e comportamentos cada vez mais complexos. Com isto, historicamente o $\mathrm{H}$ omem edificou-se a ponto de, ao lado do seu corpo natural, construir-se em uma outra dimensão, ao qual o filósofo denominou de corpo inorgânico, entidade que comporta uma consciência sofisticada e capacitada para planejar ações relativas ao trabalho produtivo e à organização social (M arx, 1967:292).

A divisão capitalista da sociedade e o grau de exploração do trabalho que lhe é condizente, entretanto, gerou uma espécie de empobrecimento do corpo inorgânico já que o proletário passou a ser controlado intensivamente pelos interesses da produção, inclusive no período da vida que passa afastado do ambiente fabril. Com isto, ainda segundo $M$ arx, a liberdade de pensar e de se apresentar como produtor de um saber eficiente foi sendo confinada a estreitos limites, impondo que o corpo inorgânico deixasse de explorar toda sua potencialidade. Paral elamente e complementando o processo de alienação imposto, o próprio corpo físico tornou-se objeto de uma exploração cada vez mais intensa e sutil, resultando no estreitamento da autonomia do proletariado, no embrutecimento do corpo do trabalhador e em graves prejuízos à saúde. M esmo que reducionista, a proposta marxista frutificou nas últimas décadas em novos posicionamentos que tocam sobretudo os fatores levados em consideração nas pesquisas empenhadas em explicar o adoecimento. A constituição da linha de estudo auto-denominada Epidemiologia Social tem buscado compreender a abrangência do processo que leva do estado de saúde ao de enfermidade através da análise minuciosa das condições materiais de vida e de trabalho específicos das classes sociais e impostas pelo modo de produção capitalista e não como fruto do acaso ou das circunstâncias individuais da existência (Breihl, 1995; H erzlich, 1996).

Concomitantemente ao enfoque marxista, no final do século XIX, o corpo passou a ser verificado por alguns pioneiros das Ciências Sociais como referencial através dos qual poder-seia predizer o estágio civilizatório em que se situavam as diferentes coletividades. Impregnada de val ores europocêntricos, a antropologia oitocentista preferiu entender tal fenômeno como um processo natural, de cunho biológico e resultante da própria evolução psicofisiológica da espécie. Assim, o fato de grupos tribais africanos sentarem-se sobre os calcanhares em vez de utilizarem cadeiras como os ocidentais, foi denunciado como uma incapacidade anatômica e mental, definindo através disto a posição ocupada pelas sociedades numa pre tensa escala cultural (Rony, 1996:217).

Esta perspectiva, bem mais que a marxista, foi amplamente difundida e invocada por uma legião de pesquisadores por mais de meio século. Em meados da década de 1930, 0 
antropólogo $\mathrm{M}$ arcel $\mathrm{M}$ auss buscou reequacionar a questão, atribuindo ao corpo mais do que uma essência biológica, uma dimensão social. Para este estudioso, a sociedade articula técnicas corporais condizentes com valores e necessidades culturais específicas, ditando os parâmetros tidos como "normais" de alimentação, sexualidade, vestimenta e apresentação pública. D esta forma, os parâmetros sócio-culturais validados coletivamente (a externalidade do corpo) foram correlacionados com o desempenho orgânico (a internalidade corpórea, inclusive os aspectos psíquicos). Abriase assim a primeira possibilidade realmente eficiente para o entendimento do corpo como uma experiência ao mesmo tempo pessoal e coletiva e, mais do que isto, a oportunidade de associar as dimensões sociais e biológicas no entendimento da existência humana (M auss, 1974).

Seguidor em larga escala dos pressupostos estabelecidos por M auss, o pensamento estruturalista, dominante nas Ciências Sociais a partir da década de 1960, enfatizou duas linhas de pesquisas que têm o corpo como um de seus aspectos privilegiados. A primeira linha, representada sobretudo pelo antropólogo Claude Lévi-Strauss, destacou o caráter simbólico e a repre sentação social no mais das vezes inconsciente do corpo e do que a ele se refere, mesmo indiretamente, tais como os desejos, os prazeres, a dieta e sua apresentação social, associando esta gama de situações efenômenos com as estruturas básicas da cultura e dos valores sociais. Paralelamente, Lévi-Strauss enfatizou um vasto campo de ambigüidades que favoreciam e ditavam os rumos da participação do indivíduo no tecido social, já que a cisão entre natureza e cultura propiciou uma situação na qual a espontaneidade do sujeito social, em muito ditada ou encenada pelo corpo, foi sendo restrita em nome do respeito às regras do viver em grupo (Lévi-Strauss, 1975).

Em outra vertente estruturalista, o filósofo M ichel Foucault salientou a fluidez dos dispositivos disciplinares que, baseados nas idéias de normal e patológico, têm historicamente ditado os comportamentos sociais como também induzido as possibilidades do saber e da prática médico-biológica. A opção social por uma cultura que tem como um dos seus eixos centrais o princípio de equilíbrio do comportamento através da contenção dos impulsos do corpo reificou a noção de razão que, ao se opor à naturalidade do corpo, produziu um discurso puritano que silencia sobre o prazer e, por contigüidade, reduz o corpo a uma simples máquina que, comple xa, exige que sua análise se realize pela decomposição acadêmica do objeto sem que contudo se chegue, no final desta operação, a uma visão holística que una o físico e o psicológico, o fisiológico e o social. N esse contexto, adverte Foucault, "o interessante não éver que projeto está na base de tudo isso, mas em termos de estratégia, como as peças foram dispostas" (Foucault, 1979:152).

Afora esses enfoques, na década de 1930 despontou ainda uma outra possibilidade de entendimento do corpo através da noção de corporalidade, tendo como principal fomentador o filósofo e psicólogo M aurice M erleau-Ponty. Retomada nas últimas décadas, a proposta fenomenológica entende por corporalidade a experiência individual com o próprio corpo como forma de percepção inicialmente subjetiva e em seguida objetiva da realidade. Através disto, pontificou-se que, diferentemente dos racionalistas clássicos e também do pensamento marxista, a máxima "penso, logo existo" deveria ser substituída pela que diz "tenho corpo, logo existo". N esse sentido, as análises fenomenológicas realocaram o papel do corpo, situando-o estrategicamente como elemento mediador entre a realidade externa e a consciência individual. Se as "coisas do mundo" chegam ao indivíduo através dos sentidos, isto é, da potencialidade corporal, a razão (ou o espírito, como queria D escartes) não se mostra antagônica ao corpo mas sim seu complemento na arquitetura da existência singular (M erleau-Ponty, 1996). 
Corpo e espírito, pois, definem-se como uma unidade constituída por elementos interdependentes e indissociáveis; qual quer tentativa, mesmo acadêmica, de compartimentação tem como conseqüência uma perversora simplificação do que é tomado como objeto de estudo. Resultante da participação conjunta do corpo e do espírito, a "consciência do meu existir" é produto tanto da vida psicológica e da inserção individual nas estruturas sociais quanto do funcionamento biológico e da apresentação pública do corpo. Através dela, chegase também à consciência do mundo e, por conseguinte, do "meu estar no mundo", do poder e dos limites das ações individuais (Lain Entralgo, 1984:130; C sordas, 1996).

\section{C onsiderações finais}

A rejeição, ou pelo menos a dificuldade dos professores e de seus alunos em dialogarem sobre o corpo para além dos quadros que tradicionalmente foram arquitetados pelas Ciências Biológicas, tem como pano de fundo o próprio cenário cultural que a civilização ocidental traçou acerca do discurso sobre a corporalidade e a corpolatria. $N$ um contexto em que sobretudo a mídia invoca insistentemente sobre o corpo, deslocar o foco de questionamento para o corpo individualizado e concreto e as questões que ele suscita para além das idealizações midiáticas ainda constrange, independentemente da faixa etária. Estabelece-se então uma ambigüidade: usado como estratégia de venda de mercadorias pela mídia, o corpo personalizado que sugere prazeres e receios inibe a fala e dificulta a comunicação.

No ambiente de sala de aula, tal dificuldade de comunicação encontra como canal de discussão o corpo exposto segundo os model os estabelecidos pela anatomia, fisiologia e patologia, perspectivas que, se importantes, não correspondem às ansiedades de alunos adolescentes que buscam mais informações para compreenderem os enigmas produzidos pelos seus corpos e, em continuidade, de suas próprias vidas. Em consonância com as novas propostas estabele cidas pelos Parâmetros C urriculares $\mathrm{N}$ acionais, acredita-se que esta ausência de correspondência entre o que é ensinado e o que se busca aprender aflora como um dos principais elementos obstaculizadores do processo pedagógico. A nosso ver, ele tem como tarefa central contribuir para a constituição do educando enquanto sujeito em si, isto é, portador de uma identidade singular e, ao mesmo tempo, como sujeito social participante na coletividade em que se situa.

As teorias sociais aqui expostas em seus pontos básicos, por óbvio, não substituem o conhecimento proposto pela Biologia e pelos saberes que Ihe são correlatos e nem é esta a nossa proposta aqui assumida. Advoga-se sim que os enfoques produzidos pelas Ciências Sociais podem ser úteis como ferramentas iniciais para, a partir da problemática cotidiana vivenciada pelos discentes, servir de ponte entre o que se ensina e o que se espera aprender, entre o corpo como produto social e o corpo como um dos objetos privilegiados pela Biologia. Assumido como tema complexo, o corpo incita a aproximação de docentes de diferentes áreas do conhecimento, enfatizando a necessidade e a urgência de trabaIhos multi e transdiciplinares. Tanto quanto 0 enfoque do organismo pelas lentes da Biologia, a perspectiva histórico-antropológica sobre o mesmo objeto desdobra-se em complexas e diferenciadas linhas analíticas, exigindo a associação de especialistas de diversas formações para o sucesso da proposta de ensino.

Assim, a possibilidade didático-pedagógica aberta com a incorporação docente das teorias sociais sobre o corpo permite a confluência das discussões da cultura pessoal e da cultura 
científica dos alunos e dos professores e, a partir disto, favorecendo a ampliação e eficiência do diálogo entre os personagens envolvidos no ato pedagógico. Acredita-se que, a partir disso, abre-se uma nova frente para o desempenho eficiente das ações pedagógicas que, a nosso ver, têm como objetivo último a compreensão do H omem e do Mundo.

\section{Referências bibliográficas}

BREIH L, J. , GRAN D A, E. Saúde na Sociedade. São Paulo, H U CIT EC/ED U N ESP, 1995. COD O, W., SEN N E , W.A. 0 que éa corpolatria. São Paulo, Brasiliense, 1985.

CSO RD AS, T. J. The body as representation and being-in-the-world. In: CSO RDAS, T.J. (Ed.). Embodiment and Experience: the Existencial ground of culture and self. Cambridge, Cambridge University Press, 1996, pag. 1-24.

FO U CAULT, M. Microfísica do poder. Rio de Janeiro, Graal, 1979.

GALLAGHER, C. La bio-economia de nuestro común amigo. In: FEHER, M . et al. (Ed.)

Fragmentos para una historia del cuerpo humano. M adrid, Taurus, 1992. v. 3. 344-365.

GUISTAN, G. Didáctica e comunicação. Porto, ASA, 1994.

HERZLICH , C. Santé et maladie: analyse d'une représentation sociale. Paris, École des H autes Études en Sciences Sociales, 1996.

JEAN, G. Cultura pessoal e acção pedagógica. Porto, ASA, 1990.

LAIN -EN TRALGO, P. Antropologia medica. Barcelona, Salvat, 1984.

LÉVI-ST RAUSS, C. Antropologia estrutural. Rio de Janeiro, Tempo Brasileiro, 1975.

M ARX, K. Writings of the young M arx on philosophy and society. N ew York, Free Press, 1967. M AUSS, M . Sociologia e antropologia. São Paulo, EPU/ED U SP , 1994. v. 2, pag. 209-217. M ERLEAU U -PO N TY, M. Fenomenologia da percepção. São Paulo, M artins Fontes, 1996. POSTIC, M . 0 imaginário na relação pedagógica. Porto, ASA, 1992.

RO DRIGUES, J. C. Tabu do corpo. Rio de Janeiro,Achiamé, 1979. . O corpo na história. Rio de Janeiro, Fiocruz, 1999.

RONY, F. T. The third eye: race, cinema and ethnographic spetacle. D urham, D uke University Press, 1996.

TURN ER, B. S. The body \& society. N ew York, Basil Blackwell, 1984. 
